\title{
Expansion of health insurance in Moldova and associated improvements in access and reductions in direct payments
}

\author{
Thomas Hone ${ }^{1}$, Jarno Habicht ${ }^{2}$, \\ Silviu Domente ${ }^{3}$, Rifat Atun ${ }^{4}$ \\ ${ }^{1}$ Department of Primary Care and Public Health, \\ Imperial College, London, UK \\ ${ }^{2}$ WHO Country Office in Kyrgyzstan, World \\ Health Organization \\ ${ }^{3}$ WHO Project Office in Greece, World Health \\ Organization \\ ${ }^{4}$ Harvard T. H. Chan School of Public Health, \\ Boston, MA, USA
}

Background Moldova is the poorest country in Europe. Economic constraints mean that Moldova faces challenges in protecting individuals from excessive costs, improving population health and securing health system sustainability. The Moldovan government has introduced a state benefit package and expanded health insurance coverage to reduce the burden of health care costs for citizens. This study examines the effects of expanded health insurance by examining factors associated with health insurance coverage, likelihood of incurring out-of-pocket (OOP) payments for medicines or services, and the likelihood of forgoing health care when unwell.

Methods Using publically available databases and the annual Moldova Household Budgetary Survey, we examine trends in health system financing, health care utilization, health insurance coverage, and costs incurred by individuals for the years 2006-2012. We perform logistic regression to assess the likelihood of having health insurance, incurring a cost for health care, and forgoing health care when ill, controlling for socio-economic and demographic covariates.

Findings Private expenditure accounted for $55.5 \%$ of total health expenditures in 2012. 83.2\% of private health expenditures is OOP payments-especially for medicines. Healthcare utilization is in line with EU averages of 6.93 outpatient visits per person. Being uninsured is associated with groups of those aged 25-49 years, the selfemployed, unpaid family workers, and the unemployed, although we find lower likelihood of being uninsured for some of these groups over time. Over time, the likelihood of OOP for medicines increased (odds ratio $\mathrm{OR}=1.422$ in 2012 compared to 2006), but fell for health care services ( $\mathrm{OR}=0.873$ in 2012 compared to 2006). No insurance and being older and male, was associated with increased likelihood of forgoing health care when sick, but we found the likelihood of forgoing health care to be increasing over time (OR=1.295 in 2012 compared to 2009).

Conclusions Moldova has achieved improvements in health insurance coverage with reductions in OOP for services, which are modest but are eroded by increasing likelihood of OOP for medicines. Insurance coverage was an important determinant for health care costs incurred by patients and patients forgoing health care. Improvements notwithstanding, there is an unfinished agenda of attaining universal health coverage in Moldova to protect individuals from health care costs. 
Moldova is the poorest country in Europe. Following independence from the Soviet Union in 1991, Moldova experienced rapid economic decline and has faced economic challenges since, hampering government efforts aimed at health system strengthening, financial sustainability, and universal health coverage (UHC) $[1,2]$ - the sustainable development goals (SDGs) for health [3].

The economic downturn in Moldova led to health system funding shortages, reductions in service provision, increased out-of-pocket payments for users [4], and a rise in tobacco and alcohol use. Life expectancy at birth fell from 69 years in 1989 to 66 years in 1995, and the health burden from infections (particularly tuberculosis) and chronic illness rose [5,6]. Adverse economic conditions led to emigration, with the resident population of Moldova falling from 3.62 million in 2003 to 3.56 million in 2013 [7]. In 2006 , around $20 \%$ of the population lived on less than US $\$ 2$ (purchasing power parity) a day [8], while gross domestic product (GDP) per capita was US\$ 1967 in 2011the lowest in geographical Europe [5]. The GDP has increased from US $\$ 1.3$ billion in 2000 to US $\$ 7.3$ billion in 2012 [9], but approximately one quarter comes from remittances from Moldovan population working abroad [8].

The government of Moldova has embarked on health system reforms aimed at rationalising excess hospital capacity [6], reducing service duplication and developing primary health care (PHC) [4] in order to improve health outcomes, provide financial protection and achieve financial sustainability. The Health Sector Strategy for 1997-2003 [4] set out plans to develop an efficient, effective, responsive and equitable health system [10-12]. Following the 1994 Constitution, which guaranteed a right to health, a state-funded free health service package was introduced in $1999[4,6]$, followed by the Law on Mandatory Health Insurance (MHI) in 2001, and the establishment of the National Health Insurance Company (CNAM) in 2004 [4].

The MHI is compulsory for Moldovan citizens-and aims to provide complete insurance coverage-but in reality individuals may choose their own insurance or not to purchase any [4]. Certain individuals (non-working groups including students, children, pensioners, disabled etc.) receive insurance coverage without payment covered by the government [4]. MHI coverage entitles individuals to a benefits package of covered services-including selected primary and secondary care services, emergency care, and dental services. In 2009, primary care services were extended, free of charge, to all irrespective of insurance status, and in 2012, services covered by the benefit package were further extended [4]. Nonetheless, many medicines are not covered and patients incur informal payments due to limited financing of the benefit package $[4,13]$. The $\mathrm{Na}$ tional Health Policy 2007-2021 [14] was followed by the
Healthcare Development Strategy 2008-2017 [15] which, alongside wider health system reform, specifically aimed to expand insurance coverage through financial incentives and mandating an insurance policy when renewing government issued licenses [4].

Earlier studies highlight the significant burden of OOP incurred for hospital services (mostly due to informal payments) and for medicines [13] (Box 1). This study uses routine administrative data on insurance coverage and health care utilization, and household surveys to explore the effect of health system reforms on OOP, and applies robust econometric methods to analyze the likelihood of being uninsured, incurring an OOP for medicines or health services, or forgoing health care by socio-economic and demographic characteristics.

Box 1 Health System Financing in Moldova

Trends in health system financing: Total health expenditure (THE) as a percentage of GDP rose from $8.1 \%$ in 2002 to $11.72 \%$ in 2012 . While higher than the EU average of $9.61 \%$ in 2012, the absolute level of health expenditure per person (PPP\$) is the lowest in Europe at US\$ 344, compared with the EU average of US\$ 3307 [5].

In 2012, health expenditure from public sources was $45.5 \%$ of THE compared to the EU average of $76.0 \%$, illustrating the large role private sources play. Public sector expenditure on health as a proportion of total government expenditure rose from $11.7 \%$ in 2007 to $13.3 \%$ in 2012 - similar to the EU average of $15.2 \%$ [5].

The majority of private health expenditures ( $83.2 \%$ in 2012) is OOP and has risen from $79.9 \%$ in 2003 . Pharmaceutical expenditures accounted for $72 \%$ of the OOP payments in 2010 [16].

Purchaser-provider split: In 2003, the creation of CNAM introduced a purchaser-provider split in Moldovan health system by separating health financing and service delivery. CNAM is responsible for direct contracting of hospitals and PHC providers, and for $85 \%$ of the government expenditure on health [17]. Of this expenditure, around 49\% was spent on hospitals, $29 \%$ on PHC, $9 \%$ on ambulance services, $7 \%$ on specialized outpatient care, $4 \%$ on compensated outpatient medicines, and $2 \%$ on complex health care services (2011 data), with little variation in these proportions since 2007 [17].

Geographical variation in health system financing: Healthcare spending across regions (rayons) has been uneven, with per capita funding across rayons in 2003 differing by a factor of 4.6. Urban rayons received a substantially greater share of funds due to concentration of hospital and specialist care. Following financial reorganization in 2004 that centralised pooling of funds with CNAM, in 2010 the difference fell to 3.8 [17] 


\section{METHODS}

\section{Analytical framework}

This study uses a health systems framework $[16,17]$ to guide the analysis (Box 2). The framework builds on earlier approaches used to analyze health system reforms $[18,19]$. The national Healthcare Development Strategy 2008-2017 follows a similar structure to the health systems framework used in the study, enabling analysis of the changes in the health system goal of financial protection following health system reforms aimed at expanding insurance coverage and exploring the association of insurance

Box 2 Health System Framework used for analysis

Health system functions: We identify four key health system functions which the policy makers can modify to achieve health system goals: (i) governance and organization - the policy and regulatory environment, stewardship function of the ministry of health and its relationship with other levels of the health system, and structural arrangements for insurers/purchasers, health care providers and market regulators; (ii) financing - how the funds are collected, funds and risks pooled, finances allocated within the health system and how health care providers are remunerated; (iii) resource management - how physical, human and intellectual resources are generated and allocated, including their geographic and needs-based allocation; and (iv) service delivery that includes both public health services and individual health services provided within the community, PHC, hospitals, and other health institutions. Health services are produced using governance and organization, financing and resource management functions.

Health system objectives: We define four objectives which the policy makers need to balance in relation to individual and public health services: equity (including access and use of services by different population groups), efficiency (efficient allocation of resources to right interventions and producing them at low cost), effectiveness (the extent to which interventions provided are evidence based and safe) and responsiveness (of care providers to user needs, including choice of providers).

Health system goals: There are three health system goals in our framework which the system aims to achieve. The first goal is health, both the level and distribution of population health as measured by morbidity and mortality. The second goal is financial protection, for which we examine the level and distribution of health expenditures (targeting of health insurance), levels of health insurance coverage, and levels of financial protection (out of pocket expenditures, and catastrophic health expenditures) for different population segments. The third goal is user satisfaction, specifically the satisfaction of the population with the health system. coverage with service utilization, OOP payments incurred and forgone health care.

\section{Data sources}

Two main sources of data were used for the years 20062012. First, publically available datasets from the Moldovan National Center for Health Management (CNMS) were collected. CNMS collates data from public health care provider reports. We extracted health service utilization information relating to number of hospitalisations, average number of visits per person, and emergency calls per 1000 residents.

Second, the monthly Household Budget Survey (HBS) was used. The HBS is based on an internationally validated survey and is undertaken by the Moldovan National Bureau of Statistics (NBS) [7]. The HBS is nationally representative and is undertaken through two-stage sampling based on regional areas and a random selection of households. Approximately 5500 households (15000 individuals) are surveyed annually on a wide range of questions relating to the economic situation of the household and individuals. Responses for the years 2006-2012 were obtained from the NBS. We selected questions relevant to this analysis including demographic, socio-economic, health and health carerelated questions. Our outcome variables of interest were calculated from survey questions: "If individuals currently have health insurance"; "if individuals paid for any service (inpatient or outpatient) either formally or informally when using care in the last four weeks", and "if you were unwell in the last four weeks, but did not use healthcare". Because of issues of non-response (up to $40 \%$ in some years), the age and gender distribution of the HBS was compared to national population data (from NBS [7]) showing high similarity.

\section{Analysis}

Using the health system analytical framework [14,15], we examine elements of financial protection in the context of the health system objectives. Equity is a key health system objective for this analysis. We examine equity in insurance status, OOP payments, and foregone health across demographic groups. We demonstrate the interactions between insurance status and equity in other financial protection elements such as OOP. Additionally, we also explore the health system objectives of responsiveness in terms of preferred health care provider, effectiveness through forgone health care, and efficiency in terms of national utilization trends. We triangulate these findings to understand how factors contributing to financial protection are being met.

\section{Descriptive analysis}

CNMS data on health care utilization are shown over time. Individual responses on preferred of health care provider, 
for those with health care use in the last four weeks, were stratified by provider and year.

For insurance coverage, CNMS data was compared with individual HBS responses (stratified by employed status and age groups) over time.

Insurance coverage trends were compared between individual HBS responses and from administrative data (CNMS) sources. Furthermore, we stratified the insurance status of the respondents in the HBS by occupation and age group.

The percentages of individuals reporting OOP payments were described by consultative services, inpatient services and drugs, and by each year. Mean incurred costs by individuals were shown. Additionally, mean costs were compared to average monthly earnings.

\section{Logistic regression}

We employed logistic regression to calculate the likelihood of: being uninsured, incurring an OOP for medicines or any health care service from health care used in the last four weeks, and not using (foregoing) health care when reporting a health problem in the last four weeks. Logistic regression was employed as the most appropriate method for binary outcomes.

Covariates from the HBS survey were used to control for and highlight explanatory factors. We included in all models: age group ( $0-17$ years, $18-24,25-34,35-49,50-59$, 60-74 and 75+); gender; chronic disease status (yes or no); employment status (employed, self-employed (non-agriculture), self-employed (agriculture), unpaid family worker, unemployed (including those not of working age); and educational attainment (pre-school or no education, primary, secondary, and college or university). We also included year (2006-2012) to look for time trends.

For the regressions on the likelihood of an OOP and forgone health care, we included disability (yes or no) and uninsured (yes or no) as covariates. Additionally, for the regressions on the likelihood of an OOP we included first choice of health care provider (family doctor's office, home visit, polyclinic (health center), hospital or other (eg, pharmacy). For the regression of foregone health care, we only examined the years 2009-2012, as the question was not in earlier surveys. Analyses were carried out at the individual level, with adjustments for the clustered nature of the survey. All individual responses were included for analyses, except the likelihood of being uninsured. The regression was restricted to those aged over 18 and under the age of 60 years, as individuals outside these ages are eligible for free insurance coverage. We report adjusted odds ratios and 95\% confidence intervals. Interaction terms between covariates and year (linear trends) were additionally tested.

\section{RESULTS}

Table 1 shows the descriptive statistics, which categorises the respondents by socio-economic and demographic covariates, and additionally overall responses to key variables of interest.

\section{Service utilization}

We examined average health care utilization rate at the national level and preferred first contact provider from HBS respondents. The health care utilization rate at the national level rose between 2006 and 2012 (Table 2), with the hospitalization rate (per 100 residents) increasing from 16.7 in 2006 to 18.4 in 2012 and the average number of outpatient visits per person rising from 6.02 to 6.45 . These numbers are broadly in line with European averages (of 18.04 hospitalisations and 6.93 outpatient visits per person in 2012) [5].

Responses in the HBS from individuals who sought health care in the last four weeks show the majority sought health care in former polyclinics (centers that in majority of cases include both family doctors and out-patient specialists) (48.0\% in 2012) with family doctor offices (32.6\%), home visits (8.9\%) and hospitals (5.2\%). These trends have remained fairly constant since 2003 (Figure 1).

\section{Insurance coverage}

Approximately $75 \%$ of HBS from individuals respondents reported having health insurance during the period 20062012 (Table 3). National statistics suggest rising coverage of health insurance from $76.1 \%$ to $80.3 \%$. In 2012 , only $60 \%$ of the working age population (18-59 years) had insurance coverage, with the self-employed and those working in family business having lower coverage levels: $24 \%$ of self-employed agriculture workers, $57.8 \%$ of self-employed nonagriculture workers, and $53.8 \%$ of unpaid family workers had insurance. In 2012, the main reasons for being uninsured were unemployment (27.9\%), cost (26.2\%), "they would pay for healthcare anyway" (13.9\%), working informally (13.1\%), "belief that it would not be needed" (8.5\%) and working abroad (8.1\%).

The odds of not having health insurance were examined using multivariate logistic regression (Table 4). Age was an important determinant of being uninsured, with those aged 25-43 and 35-49 years of age, respectively, $2.9(\mathrm{OR}=2.898$, $P<0.001)$ and 2.3 times $(\mathrm{OR}=2.261, P<0.001)$ more likely to be uninsured than those aged $18-24$ or $50-60$ years of age.

Females were less likely to be uninsured than men $(\mathrm{OR}=0.599, P<0.001)$, as were those with chronic health conditions ( $\mathrm{OR}=0.303, P<0.001$ ). All categories of employment were substantially more likely to be uninsured 
Table 1. Numbers and percentage distribution of Household Budget Survey (HBS) respondents by year (2006-2012), socio-economics and demographics, and key variables of interest

\begin{tabular}{|c|c|c|c|c|c|c|c|c|c|c|c|c|c|c|}
\hline & \multicolumn{2}{|c|}{2006} & \multicolumn{2}{|c|}{2007} & \multicolumn{2}{|c|}{2008} & \multicolumn{2}{|c|}{2009} & \multicolumn{2}{|c|}{2010} & \multicolumn{2}{|c|}{2011} & \multicolumn{2}{|c|}{2012} \\
\hline & No. & $\%$ & No. & $\%$ & No. & $\%$ & No. & $\%$ & No. & $\%$ & No. & $\%$ & No. & $\%$ \\
\hline \multicolumn{15}{|l|}{ Age group (years): } \\
\hline $0-17$ & 4560 & 28.2 & 4507 & 27.2 & 4383 & 26.7 & 3974 & 26.4 & 3703 & 25.8 & 3577 & 24.4 & 3424 & 24.5 \\
\hline $18-24$ & 1488 & 9.2 & 1626 & 9.8 & 1539 & 9.4 & 1509 & 10.0 & 1303 & 9.1 & 1319 & 9.0 & 1203 & 8.6 \\
\hline $25-34$ & 1771 & 11.0 & 1871 & 11.3 & 1780 & 10.8 & 1684 & 11.2 & 1607 & 11.2 & 1728 & 11.8 & 1589 & 11.4 \\
\hline $35-49$ & 3299 & 20.4 & 3186 & 19.2 & 3152 & 19.2 & 2870 & 19.1 & 2702 & 18.8 & 2627 & 17.9 & 2467 & 17.7 \\
\hline $50-59$ & 2311 & 14.3 & 2514 & 15.2 & 2601 & 15.8 & 2345 & 15.6 & 2273 & 15.8 & 2440 & 16.7 & 2352 & 16.8 \\
\hline $60-74$ & 2027 & 12.5 & 2063 & 12.4 & 2124 & 12.9 & 1910 & 12.7 & 2072 & 14.4 & 2151 & 14.7 & 2174 & 15.6 \\
\hline $75+$ & 707 & 4.4 & 822 & 5.0 & 841 & 5.1 & 774 & 5.1 & 719 & 5.0 & 817 & 5.6 & 765 & 5.5 \\
\hline \multicolumn{15}{|l|}{ Sex: } \\
\hline Male & 7477 & 46.3 & 7666 & 46.2 & 7514 & 45.8 & 6960 & 46.2 & 6692 & 46.5 & 6720 & 45.8 & 6428 & 46.0 \\
\hline Female & 8686 & 53.7 & 8923 & 53.8 & 8906 & 54.2 & 8106 & 53.8 & 7687 & 53.5 & 7939 & 54.2 & 7546 & 54.0 \\
\hline \multicolumn{15}{|l|}{ Chronic condition: } \\
\hline Yes & 3861 & 23.9 & 4112 & 24.8 & 4303 & 26.2 & 3993 & 26.5 & 4253 & 29.6 & 4038 & 27.6 & 4241 & 30.4 \\
\hline No & 12302 & 76.1 & 12477 & 75.2 & 12109 & 73.8 & 11073 & 73.5 & 10126 & 70.4 & 10621 & 72.5 & 9733 & 69.7 \\
\hline \multicolumn{15}{|l|}{ Employment status: } \\
\hline Employed & 4339 & 26.9 & 4525 & 27.3 & 4540 & 25.5 & 4061 & 25.2 & 3849 & 25.0 & 3987 & 27.2 & 3681 & 26.3 \\
\hline Self-employed non-agriculture & 516 & 3.2 & 428 & 2.6 & 475 & 2.7 & 473 & 2.9 & 440 & 2.9 & 526 & 3.6 & 480 & 3.4 \\
\hline Self-employed agriculture & 2661 & 16.5 & 3048 & 18.4 & 2892 & 16.2 & 3037 & 18.9 & 3393 & 22.1 & 4095 & 27.9 & 4339 & 31.1 \\
\hline Unpaid family worker & 350 & 2.2 & 354 & 2.1 & 242 & 1.4 & 252 & 1.6 & 244 & 1.6 & 295 & 2.0 & 288 & 2.1 \\
\hline Unemployed & 8297 & 51.3 & 8234 & 49.6 & 9671 & 54.3 & 8265 & 51.4 & 7453 & 48.5 & 5756 & 39.3 & 5186 & 37.1 \\
\hline \multicolumn{15}{|l|}{ Education: } \\
\hline Pre-school or none & 2365 & 14.6 & 2378 & 14.3 & 3682 & 20.7 & 3140 & 19.5 & 3039 & 19.8 & 2043 & 13.9 & 1943 & 13.9 \\
\hline Primary & 2351 & 14.6 & 2307 & 13.9 & 2253 & 12.6 & 1965 & 12.2 & 1750 & 11.4 & 1711 & 11.7 & 1516 & 10.9 \\
\hline Secondary & 8249 & 51.0 & 8503 & 51.3 & 8497 & 47.7 & 7971 & 49.6 & 7735 & 50.3 & 7832 & 53.4 & 7705 & 55.1 \\
\hline College or university & 3198 & 19.8 & 3401 & 20.5 & 3388 & 19.0 & 3012 & 18.7 & 2855 & 18.6 & 3073 & 21.0 & 2810 & 20.1 \\
\hline \multicolumn{15}{|l|}{ Disabled: } \\
\hline No & 15303 & 94.7 & 15676 & 94.5 & 15519 & 87.1 & 14135 & 87.9 & 13501 & 87.8 & 13710 & 93.5 & 13027 & 93.2 \\
\hline Yes & 860 & 5.3 & 913 & 5.5 & 2301 & 12.9 & 1953 & 12.1 & 1878 & 12.2 & 949 & 6.5 & 947 & 6.8 \\
\hline \multicolumn{15}{|l|}{ Uninsured: } \\
\hline No & 12390 & 76.7 & 12656 & 76.3 & 12718 & 71.4 & 11368 & 70.7 & 10879 & 70.7 & 11116 & 75.8 & 10593 & 75.8 \\
\hline Yes & 3773 & 23.3 & 3933 & 23.7 & 5102 & 28.6 & 4720 & 29.3 & 4500 & 29.3 & 3543 & 24.2 & 3381 & 24.2 \\
\hline \multicolumn{15}{|l|}{ First choice provider: } \\
\hline Home visit & 157 & 6.6 & 137 & 6.0 & 210 & 10.7 & 251 & 11.0 & 220 & 9.5 & 251 & 10.3 & 219 & 8.9 \\
\hline Family doctor office & 792 & 33.3 & 656 & 28.7 & 479 & 24.4 & 665 & 29.2 & 633 & 27.4 & 633 & 26.0 & 799 & 32.6 \\
\hline Polyclinic health center $\dagger$ & 1235 & 52.0 & 1302 & 57.0 & 1071 & 54.5 & 1084 & 47.6 & 1185 & 51.3 & 1201 & 49.3 & 1176 & 48.0 \\
\hline Hospital & 185 & 7.8 & 185 & 8.1 & 202 & 10.3 & 216 & 9.5 & 193 & 8.4 & 181 & 7.4 & 127 & 5.2 \\
\hline Other (eg, pharmacy & 7 & 0.3 & 5 & 0.2 & 3 & 0.2 & 62 & 2.7 & 77 & 3.3 & 172 & 7.1 & 128 & 5.2 \\
\hline \multicolumn{15}{|c|}{ Sought health care in last 4 weeks: } \\
\hline Yes & 2376 & 14.7 & 2285 & 13.8 & 1965 & 13.0 & 2278 & 15.1 & 2308 & 16.1 & 2438 & 16.6 & 2449 & 17.5 \\
\hline No & 13787 & 85.3 & 14304 & 86.2 & 13202 & 87.0 & 12788 & 84.9 & 12071 & 84.0 & 12221 & 83.4 & 11525 & 82.5 \\
\hline Any out-of-pocket for drugs: & & & & & & & & & & & & & & \\
\hline No & 11692 & 72.3 & 12003 & 72.4 & 13116 & 73.6 & 11610 & 72.2 & 10797 & 70.2 & 10245 & 69.9 & 9584 & 68.6 \\
\hline Yes & 4471 & 27.7 & 4586 & 27.6 & 4704 & 26.4 & 4478 & 27.8 & 4582 & 29.8 & 4414 & 30.1 & 4390 & 31.4 \\
\hline Any out-of-pocket for service & & & & & & & & & & & & & & \\
\hline No & 15632 & 96.7 & 16097 & 97.0 & 17199 & 96.5 & 15626 & 97.1 & 14935 & 97.1 & 14280 & 97.4 & 13562 & 97.1 \\
\hline Yes & 531 & 3.3 & 492 & 3.0 & 621 & 3.5 & 462 & 2.9 & 444 & 2.9 & 379 & 2.6 & 412 & 3.0 \\
\hline Foregone health care*: & & & & & & & & & & & & & & \\
\hline No & - & - & - & - & - & - & 2190 & 63.7 & 1607 & 57.0 & 2376 & 62.1 & 2333 & 57.4 \\
\hline Yes & - & - & - & - & - & - & 1250 & 36.3 & 1214 & 43.0 & 1453 & 38.0 & 1733 & 42.6 \\
\hline Number of respondents $(\mathrm{N})$ & 16163 & & 16589 & & 17820 & & 16088 & & 15379 & & 14659 & & 13974 & \\
\hline
\end{tabular}

*This question was not asked in the years prior to 2009.

†Polyclinics include family doctors and out-patient specialists, especially in larger cities and urban centers. 


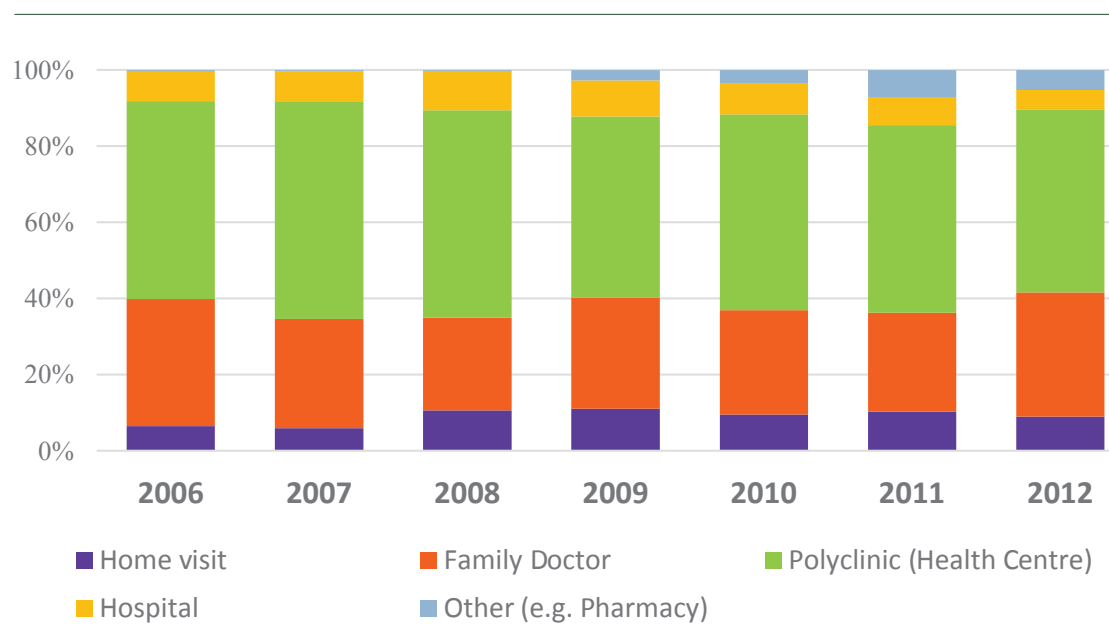

Figure 1. Choice of health care provider for individuals who sought medical care in the last four weeks (2006-12). Shows responses from individuals who sought healthcare in the last four weeks and their first preferred healthcare provider. Those seeking care at a hospital are likely underestimated due to the infrequency of events and small samples employed. Polyclinics include family doctors and outpatient specialists, especially in larger cities and urban centres. than those employed. The self-employed, and unpaid family workers were all more than 20 times more likely to be uninsured. The unemployed were 5 times more likely $(\mathrm{OR}=4.915, P<0.001)$. All categories of education were more likely to be uninsured than those with only preschool or no-education with primary, secondary, and college or university educated individuals 7.7, 6.1 and 3.2 times more likely to be uninsured.
Over time, there was no evidence of a trend in change in likelihood of being uninsured. Models with interactions with time (results not shown) suggest that the likelihood of being uninsured declined over time for those with chronic conditions (compared to those without), females (compared to males), and the self-employed (agriculture) and unpaid family workers (compared to employed). There was an increased likelihood in being uninsured for the unemployed over time (compared to other employment categories).

Table 2. Healthcare utilization (2006-2012) [20]*

\begin{tabular}{lccccccc} 
& $\mathbf{2 0 0 6}$ & $\mathbf{2 0 0 7}$ & $\mathbf{2 0 0 8}$ & $\mathbf{2 0 0 9}$ & $\mathbf{2 0 1 0}$ & $\mathbf{2 0 1 1}$ & $\mathbf{2 0 1 2}$ \\
\hline Hospitalizations per 100 residents & 16.7 & 17.2 & 17.8 & 18.0 & 18.1 & 18.5 & 18.4 \\
\hline Average number of visits per person & 6.0 & 6.2 & 6.3 & 6.3 & 6.5 & 6.4 & 6.5 \\
\hline Emergency calls per 1000 residents & 266.3 & 281.4 & 282.7 & 301.9 & 282.7 & 279.5 & 271.1 \\
\hline
\end{tabular}

*Includes responses from individuals who sought health care in the last four weeks and their first preferred health care provider. Those seeking care at a hospital are likely be underestimated due the infrequency of events and small samples employed. Polyclinics include family doctors and out-patient specialists, especially in larger cities and urban centers.

Table 3. Insurance coverage national and occupational groups (2006-2012) [7,20]

\begin{tabular}{|c|c|c|c|c|c|c|c|}
\hline & 2006 & 2007 & 2008 & 2009 & 2010 & 2011 & 2012 \\
\hline \multicolumn{8}{|c|}{ From the National Household Budget Survey (individuals): } \\
\hline National coverage & 76.7 & 76.3 & 77.5 & 75.5 & 75.7 & 75.8 & 75.8 \\
\hline \multicolumn{8}{|l|}{ By occupation: } \\
\hline - Employed & 83.3 & 85.7 & 87.1 & 85.2 & 84.6 & 84.9 & 84.1 \\
\hline - Self-employed (non-agriculture) & 19.8 & 17.1 & 20.2 & 18.8 & 22.3 & 22.6 & 24.0 \\
\hline - Self-employed (agriculture) & 32.1 & 37.3 & 39.1 & 41.3 & 45.7 & 54.7 & 57.8 \\
\hline - Unpaid family worker & 37.4 & 37.3 & 41.3 & 41.3 & 52.9 & 51.9 & 53.8 \\
\hline - Unemployed* & 92.7 & 90.3 & 76.9 & 78.2 & 78.4 & 90.7 & 91.1 \\
\hline \multicolumn{8}{|l|}{ By age group (years): } \\
\hline $0-18$ & 98.3 & 99.2 & 98.8 & 98.5 & 98.7 & 98.4 & 98.2 \\
\hline $18-24$ & 62.8 & 59.7 & 64.5 & 59.4 & 61.5 & 58.6 & 58.9 \\
\hline $25-34$ & 50.3 & 48.4 & 50.0 & 48.8 & 47.5 & 51.6 & 46.8 \\
\hline $35-49$ & 56.1 & 55.5 & 57.0 & 53.9 & 53.5 & 52.9 & 54.6 \\
\hline $50-60$ & 66.4 & 67.1 & 69.0 & 66.8 & 66.7 & 67.6 & 66.6 \\
\hline $60-74$ & 98.1 & 98.5 & 97.6 & 96.9 & 95.6 & 96.7 & 96.7 \\
\hline $75+$ & 100.0 & 100.0 & 99.9 & 99.7 & 99.9 & 99.9 & 99.6 \\
\hline \multicolumn{8}{|l|}{ From administrative data sources: } \\
\hline National coverage & 76.1 & 76.2 & 77.7 & 80.0 & 78.6 & 79.3 & 80.3 \\
\hline
\end{tabular}

*Includes those not of working age. 
Table 4. Multivariate regression results on likelihood of being uninsured for individuals aged 18-60 years (2006-2012)*

\begin{tabular}{lccc} 
& AOR & P-VAluE & 95\% CI \\
Age group: & & & \\
\hline 18-24 (Ref) & 1.000 & & \\
\hline $25-34$ & 2.898 & $<0.001$ & $2.682-3.130$ \\
\hline $35-49$ & 2.261 & $<0.001$ & $2.102-2.433$ \\
\hline $50-60$ & 1.033 & 0.409 & $0.957-1.115$ \\
\hline Sex: & & & \\
\hline Male (Ref) & 1.000 & & \\
\hline Female & 0.599 & $<0.001$ & $0.575-0.623$ \\
\hline Chronic disease: & & & \\
\hline No (Ref) & 1.000 & & \\
\hline Yes & 0.303 & $<0.001$ & $0.285-0.323$ \\
\hline Employment status: & & & \\
\hline Employed (Ref) & 1.000 & & \\
\hline Self-employed (non-agriculture) & 24.339 & $<0.001$ & $21.729-27.262$ \\
\hline Self-employed (agriculture) & 27.381 & $<0.001$ & $25.631-29.249$ \\
\hline Unpaid family worker & 23.781 & $<0.001$ & $20.583-27.476$ \\
\hline Unemployed & 4.915 & $<0.001$ & $4.590-5.262$ \\
\hline Education: & & & \\
\hline Pre-school or none (Ref) & 1.000 & & \\
\hline Primary & 7.170 & $<0.001$ & $4.170-12.327$ \\
\hline Secondary & 6.047 & $<0.001$ & $3.866-9.459$ \\
\hline College or university & 3.182 & $<0.001$ & $2.029-4.990$ \\
\hline Year: & & & \\
\hline 2006 (Ref) & 1.000 & & \\
\hline 2007 & 1.108 & 0.016 & $1.019-1.204$ \\
\hline 2008 & 0.997 & 0.949 & $0.916-1.085$ \\
\hline 2009 & 1.079 & 0.088 & $0.989-1.177$ \\
\hline 2010 & 1.008 & 0.860 & $0.921-1.103$ \\
\hline 2011 & 0.933 & 0.133 & $0.852-1.021$ \\
\hline 2012 & 0.920 & 0.074 & $0.840-1.008$ \\
\hline No. & 59151 & & \\
\hline & & & \\
\hline & & & \\
\hline & & & \\
\hline
\end{tabular}

AOR - Adjusted Odds Ratio, 95\% CI - confidence intervals

* $P<0.001$. Cluster robust standard errors used.

\section{Private and out-of-pocket expenditure}

Around 15\% of HBS respondents who sought health care reported a payment for consultative services and 2\% for inpatient care in 2012 (Table 5) compared with 20\% and $3 \%$ in 2006 respectively. The average costs for both consultative services and medicines had increased since 2006.
The factors affecting the likelihood of an OOP payment for both medicines and health care services were analyzed separately using multivariate logistic regression (Table 6).

Although low numbers and fluctuations in reported costs make conclusions difficult, there appears to be only modest reductions in costs incurred relative to average monthly earnings over time (Table 7).

\section{Out-of-pocket payment for drugs}

Older individuals (aged over 50 years), who sought health care in the last four weeks, were more likely to incur a cost than those aged under 34 years. Females were 13\% more likely to pay $(\mathrm{OR}=1.133, P=0.013)$, while those with chronic conditions were nearly 1.9 times as likely to incurring a cost $(\mathrm{OR}=1.911 \mathrm{P}<0.001)$.

Unpaid family workers and the unemployed were less likely to incur costs for medicines, as were those with primary and secondary education. Those without health insurance were 1.3 times more likely $(\mathrm{OR}=1.297, P=0.004)$ to incur an OOP for medicines compared to than those with insurance. Individuals were only less likely to incur a cost for medicines at hospitals or other services (such as pharmacies).

Over the period 2006-2012, the odds of incurring a cost for medicines have increased (up to 1.8 times more likely to incur a cost in $2011(\mathrm{OR}=1.772, \mathrm{P}<0.001)$ compared to 2006. The only significant interaction with time (results not shown) was insurance status with those without insurance increasingly more likely to pay for medicines OOP over time.

\section{Out-of-pocket payment for health care services}

Individuals who sought medical care in the last four weeks and incurred OOP payments (informally or formally) for consultative or inpatient services showed different trends to costs for drugs. Older individuals and those under 18 were least likely to incur a cost than those aged

Table 5. Percentage of individuals reporting costs for health care services and average costs incurred (2006-12) [7]

\begin{tabular}{|c|c|c|c|c|c|c|c|}
\hline & 2006 & 2007 & 2008 & 2009 & 2010 & 2011 & 2012 \\
\hline \multicolumn{8}{|c|}{ Of those who sought health care in the last 4 weeks, the percentage incurring costs (formal and informal) for: } \\
\hline Consultative services* & $20.3 \%$ & $19.7 \%$ & $23.9 \%$ & $18.4 \%$ & $16.9 \%$ & $13.8 \%$ & $14.9 \%$ \\
\hline Inpatient services & $2.9 \%$ & $3.4 \%$ & $4.7 \%$ & $2.7 \%$ & $3.1 \%$ & $2.2 \%$ & $2.3 \%$ \\
\hline Drugs & $82.6 \%$ & $83.6 \%$ & $84.1 \%$ & $86.5 \%$ & $88.3 \%$ & $91.1 \%$ & $89.2 \%$ \\
\hline \multicolumn{8}{|c|}{ Average costs incurred (in Moldovan Lei) for: } \\
\hline Consultative services & 132 & 161 & 169 & 190 & 195 & 249 & 215 \\
\hline Inpatient services & 711 & 1548 & 1132 & 1284 & 1065 & 2343 & 833 \\
\hline Drugs & 175 & 221 & 254 & 258 & 290 & 271 & 269 \\
\hline
\end{tabular}

*Consultation services include: consultations, analyses, diagnoses, treatments, physiotherapies and medical examinations; Inpatient services including treatment, admission, advice, analysis, interventions, surgery. The results include total costs for formal and informal payment (for consultative and inpatient services). Only small numbers of individuals used hospital services or reported inpatient costs meaning there may be variation across years. 
Table 6. Odds of incurring out-of-pocket expenditure for either drugs or health care services for those who sought medical care in last four weeks*

\begin{tabular}{|c|c|c|c|c|c|c|}
\hline & \multicolumn{3}{|c|}{ Drues } & \multicolumn{3}{|c|}{ HealthCare services } \\
\hline & AOR & P-Value & $95 \%$ CI & AOR & $P$-value & $95 \%$ CI \\
\hline \multicolumn{7}{|l|}{ Age group (years): } \\
\hline $0-17$ (Ref) & 1.000 & & & 1.000 & & \\
\hline $18-24$ & 0.732 & 0.016 & $0.568-0.943$ & 1.432 & 0.006 & $1.107-1.85$ \\
\hline $25-34$ & 0.747 & 0.030 & $0.575-0.972$ & 1.256 & 0.081 & $0.972-1.622$ \\
\hline $35-49$ & 1.133 & 0.338 & $0.878-1.463$ & 1.112 & 0.396 & $0.870-1.420$ \\
\hline $50-59$ & 1.575 & 0.001 & $1.219-2.036$ & 0.818 & 0.106 & $0.640-1.044$ \\
\hline $60-74$ & 2.074 & $<0.001$ & $1.650-2.607$ & 0.564 & $<0.001$ & $0.450-0.708$ \\
\hline $75+$ & 1.976 & $<0.001$ & $1.513-2.579$ & 0.336 & $<0.001$ & $0.252-0.44 \varepsilon$ \\
\hline \multicolumn{7}{|l|}{ Sex: } \\
\hline Male (Ref) & 1.000 & & & 1.000 & & \\
\hline Female & 1.133 & 0.013 & $1.026-1.251$ & 1.083 & 0.081 & $0.990-1.185$ \\
\hline \multicolumn{7}{|l|}{ Chronic disease: } \\
\hline No (Ref) & 1.000 & & & 1.000 & & \\
\hline Yes & 1.911 & $<0.001$ & $1.691-2.160$ & 1.296 & $<0.001$ & $1.160-1.448$ \\
\hline \multicolumn{7}{|l|}{ Employment status: } \\
\hline Employed (Ref) & 1.000 & & & 1.000 & & \\
\hline Self-employed non-agriculture & 0.936 & 0.734 & $0.641-1.368$ & 0.999 & 0.993 & $0.736-1.355$ \\
\hline Self-employed (agriculture) & 0.867 & 0.118 & $0.725-1.037$ & 0.884 & 0.112 & $0.759-1.029$ \\
\hline Unpaid family worker & 0.610 & 0.006 & $0.427-0.871$ & 1.016 & 0.929 & $0.717-1.440$ \\
\hline Unemployed & 0.811 & 0.013 & $0.689-0.956$ & 0.903 & 0.155 & $0.785-1.039$ \\
\hline \multicolumn{7}{|l|}{ Education: } \\
\hline Pre-school or none (Ref) & 1.000 & & & 1.000 & & \\
\hline Primary & 0.671 & $<0.001$ & $0.551-0.818$ & 1.112 & 0.345 & $0.893-1.385$ \\
\hline Secondary & 0.708 & 0.002 & $0.571-0.877$ & 1.238 & 0.066 & $0.986-1.555$ \\
\hline College or university & 0.817 & 0.104 & $0.640-1.042$ & 1.391 & 0.008 & $1.088-1.777$ \\
\hline Disabled & 1.066 & 0.478 & $0.893-1.274$ & 0.634 & $<0.001$ & $0.542-0.741$ \\
\hline Uninsured & 1.297 & 0.004 & $1.088-1.546$ & 3.833 & $<0.001$ & $3.307-4.443$ \\
\hline \multicolumn{7}{|c|}{ First contact health care provider: } \\
\hline Family doctor office (Ref) & 1.000 & & & 1.000 & & \\
\hline Home visit & 1.021 & 0.848 & $0.824-1.265$ & 0.415 & $<0.001$ & $0.324-0.531$ \\
\hline Polyclinic (health center) & 0.820 & 0.056 & $0.668-1.005$ & 2.723 & $<0.001$ & $2.192-3.381$ \\
\hline Hospital & 0.722 & 0.010 & $0.563-0.926$ & 7.205 & $<0.001$ & $5.667-9.161$ \\
\hline Other (eg, pharmacy) & 11.400 & $<0.001$ & $4.595-28.282$ & 0.081 & $<0.001$ & $0.034-0.191$ \\
\hline \multicolumn{7}{|l|}{ Year: } \\
\hline 2006 (Ref) & 1.000 & & & 1.000 & & \\
\hline 2007 & 1.041 & 0.624 & $0.886-1.223$ & 0.870 & 0.101 & $0.737-1.027$ \\
\hline 2008 & 1.071 & 0.432 & $0.902-1.271$ & 1.266 & 0.005 & $1.072-1.495$ \\
\hline 2009 & 1.226 & 0.019 & $1.034-1.454$ & 0.922 & 0.335 & $0.782-1.087$ \\
\hline 2010 & 1.418 & $<0.001$ & $1.191-1.687$ & 0.866 & 0.093 & $0.732-1.024$ \\
\hline 2011 & 1.772 & $<0.001$ & $1.469-2.138$ & 0.707 & $<0.001$ & $0.594-0.842$ \\
\hline 2012 & 1.422 & $<0.001$ & $1.189-1.700$ & 0.873 & 0.116 & $0.736-1.034$ \\
\hline $\mathrm{N}$ & 16099 & & & 16099 & & \\
\hline
\end{tabular}

AOR - adjusted odds ratio, 95\% CI - 95\% confidence intervals

* $P<0.001 ; 675.12, P<0.001$. Cluster robust standard errors used.

Table 7. Average reported health care costs compared to average monthly earnings [7]*

\begin{tabular}{llllllll} 
& $\mathbf{2 0 0 6}$ & $\mathbf{2 0 0 7}$ & $\mathbf{2 0 0 8}$ & $\mathbf{2 0 0 9}$ & $\mathbf{2 0 1 0}$ & $\mathbf{2 0 1 1}$ & $\mathbf{2 0 1 2}$ \\
Average monthly earnings (Lei) $\dagger$ & $\mathbf{1 6 9 7}$ & $\mathbf{2 0 6 5}$ & $\mathbf{2 5 3 0}$ & $\mathbf{2 7 4 8}$ & $\mathbf{2 9 7 2}$ & 3042 & 3386 \\
\hline Comparison of average reported health care costs as a proportion of average monthly earnings: & & & & & \\
\hline Consultative services & $7.8 \%$ & $7.8 \%$ & $6.7 \%$ & $6.9 \%$ & $6.6 \%$ & $8.2 \%$ & $6.4 \%$ \\
\hline Inpatient services & $41.9 \%$ & $75.0 \%$ & $44.7 \%$ & $46.7 \%$ & $35.8 \%$ & $77.0 \%$ & $24.6 \%$ \\
\hline Drugs & $10.3 \%$ & $10.7 \%$ & $10.1 \%$ & $9.4 \%$ & $9.8 \%$ & $8.9 \%$ & $8.0 \%$ \\
\hline
\end{tabular}

*Caution is needed in interpretation due to low numbers reporting inpatient costs.

$†$ Monthly earnings include any earning from salaries and employment, and other forms of income, averaged over all employees. It is adjusted for annual inflation. 
18-24. Those with chronic conditions were 1.3 times more likely to pay $(\mathrm{OR}=1.296, P<0.001)$, but those with disability were nearly $40 \%$ less likely to pay $(\mathrm{OR}=0.634$, $P<0.001)$.

Uninsured individuals were 3.8 times ( $\mathrm{OR}=3833$, $P<0.001$ ) more likely to incur an OOP payment for health services. There was no difference between employment categories while only those with college or university education were more likely to pay $(\mathrm{OR}=1.391, \mathrm{P}=0.008)$.

Those using hospitals and polyclinics respectively were 7.2 times $(\mathrm{OR}=7.205, P<0.001)$ and 2.8 times $(\mathrm{OR}=2.723$, $P<0.001)$ more likely to incur a cost than at family doctor offices. Home visits were less likely to incur a cost than family doctor office $(\mathrm{OR}=0.415, \mathrm{P}<0.001)$.

There was a general decline in the likelihood of incurring an OOP expenditure cost for services, although the difference was not significant every year. The only interaction with time (results not shown) was age with those aged 5060 years having an increased likelihood of incurring a cost over time compared to other ages.

\section{Foregone health care utilization}

Using multivariate logistic regression the likelihood of not visiting a health care provider when being sick in the last four weeks was examined (Table 8). Older individuals were more likely not to seek health care with those 75 years or more 2.4 times $(\mathrm{OR}=2.379, P<0.001)$ more likely than 0-24 year-olds. Females were $9.8 \%$ less likely to forego care $(\mathrm{OR}=0.902, P=0.003)$.

Employed and self-employed (non-agriculture) individuals were most likely to not seek health care when sick. The disabled were less likely to forego health care when sick (OR=0.819, P<0.001). Those without insurance were 1.7 times (68\%) more likely not to seek health care when sick $(\mathrm{OR}=1.680, P<0.001)$.

Over time there was an increasing likelihood of forgoing health care when sick with individuals on average 1.3 times (30\%) more likely in 2012 than 2009. There were no significant interactions between covariates and time suggesting the increasing trend in likelihood of foregoing health care applies to all individuals.

\section{DISCUSSION}

Our results indicate that aspects of financial protection in Moldova are improving, albeit slowly, but with different trajectories for certain demographic groups.

Health service utilization has gradually increased from to 6.45 visits per person in 2012-now in line with the European average of 6.93-and while the majority of individuals use some form of PHC (former polyclinics or family doctor
Table 8. Results from multivariate logistic regression on odds of not utilizing health care when unwell*

\begin{tabular}{|c|c|c|c|}
\hline & AOR & P-Value & CI \\
\hline \multicolumn{4}{|l|}{ Age group (years): } \\
\hline $0-17$ (Ref) & 1.000 & & \\
\hline $18-24$ & 1.267 & 0.063 & $0.987-1.626$ \\
\hline $25-34$ & 1.342 & 0.016 & $1.056-1.704$ \\
\hline $35-49$ & 1.680 & $<0.001$ & $1.358-2.078$ \\
\hline $50-59$ & 1.878 & $<0.001$ & $1.521-2.318$ \\
\hline $60-74$ & 2.008 & $<0.001$ & $1.656-2.435$ \\
\hline $75+$ & 2.379 & $<0.001$ & $1.972-2.872$ \\
\hline \multicolumn{4}{|l|}{ Sex: } \\
\hline Male (Ref) & 1.000 & & \\
\hline Female & 0.902 & 0.003 & $0.841-0.966$ \\
\hline \multicolumn{4}{|l|}{ Chronic disease?: } \\
\hline No (Ref) & 1.000 & & \\
\hline Yes & 1.059 & 0.244 & $0.962-1.165$ \\
\hline \multicolumn{4}{|l|}{ Employment status: } \\
\hline Employed (Ref) & 1.000 & & \\
\hline Self-employed non-agriculture & 0.967 & 0.803 & $0.742-1.260$ \\
\hline Self-employed (agriculture) & 0.793 & $<0.001$ & $0.706-0.891$ \\
\hline Unpaid family worker & 0.716 & 0.037 & $0.522-0.981$ \\
\hline Unemployed & 0.859 & 0.014 & $0.761-0.969$ \\
\hline \multicolumn{4}{|l|}{ Education: } \\
\hline Pre-school or none (Ref) & 1.000 & & \\
\hline Primary & 1.156 & 0.104 & $0.970-1.378$ \\
\hline Secondary & 0.989 & 0.907 & $0.825-1.186$ \\
\hline College or university & 0.875 & 0.180 & $0.719-1.064$ \\
\hline Disabled & 0.819 & $<0.001$ & $0.732-0.916$ \\
\hline Uninsured & 1.680 & $<0.001$ & $1.483-1.902$ \\
\hline \multicolumn{4}{|l|}{ Year: } \\
\hline 2009 (Ref) & 1.000 & & \\
\hline 2010 & 1.320 & $<0.001$ & $1.174-1.484$ \\
\hline 2011 & 1.070 & 0.231 & $0.958-1.195$ \\
\hline 2012 & 1.295 & $<0.001$ & $1.163-1.443$ \\
\hline $\mathrm{N}$ & 14156 & & \\
\hline
\end{tabular}

AOR - adjusted odds ratio, 95\% CI - 95\% confidence intervals $* P<0.001$. Cluster robust standard errors used.

offices), there has been little change over time in utilization levels for PHC services. The inefficient hospital network [21] needs to be rationalised to encourage greater use of PHC services and to develop a more efficient and effective health system.

The challenging economic environment is slowing efforts to improve financial protection-particularly in terms of equity. Our finding that insurance coverage is still not universal-impacting accessibility of services-particularly in older individuals, unemployed, agriculture workers and those of working age is in line with earlier studies [22]. Our findings illustrate that despite the government efforts to expand coverage through financial incentives to purchasing coverage and as a requirement during certain license renewals, not enough progress has been made.

Limited public finances for health are misallocated due to slow progress in tackling the inefficient hospital network 
which reinforces inequitable provision of health care services [21], and limits the ability of the government to further incentivise insurance coverage and expand the benefit package. Although overall there was no significant improvement over time in insurance coverage, the finding that particular groups-the self-employed (agriculture) and unpaid family workers-had reduced likelihood of being uninsured suggests attempts to expand coverage to these groups are having some success.

Our findings confirm earlier studies [13] that reveal the large burden OOP payments-particularly for medicines. Our results indicate the likelihood of incurring a payment has increased over time for medicines, but declined for health care services. Notably insurance status is a strong determinant of likelihood of incurring an OOP payment. The fact that many medicines are not covered by the MHI package [4] is clearly contributing to OOP burdens. The high average cost for drugs, which has increased since 2006 , is resulting in the unaffordability of medicines and high prices in both the public and private sectors [23]. Financial protection is still not being met in terms of access to medicines, but on the other hand, we see that efforts to curtail informal payments and reduce OOP in services have had some success. Earlier studies in Moldova suggest that cost as a reason for not seeking care when experiencing a health problem has fallen, but is still a major factor especially in poorer income groups [13].

The finding that health care is still being foregone suggests the minor improvements for some groups in insurance coverage and OOP for services, are not translating to improvements in health care utilization. Individuals are increasingly likely to forego health care-notably the uninsured, older, and certain groups of employed individuals. Challenges in expanding insurance coverage are clearly impacting on health care utilization, but health care utilization is also likely to be affected by the limited benefit package, health service quality and non-financial barriers to access [4]. Evidence indicates health insurance is key to protecting individuals against OOP payments and promoting health care utilization $[24,25]$, although for those in the informal sector the effects may be weaker [26].

\section{Strengths and limitations}

The HBS only provides limited insight into financial protection in Moldova over time. As a survey, certain populations-eg, traveling communities or homeless-will be not represented. The high non-response rate ( $40 \%)$ raises the issue of reliability of the survey, although the concordance of results with earlier studies and representativeness of age and sex distributions could mean the impact of the high non-response rate is low. There are also potential issues of recall or selective reporting possible. There are lim- itations in the questions asked in the survey. For example, we do not know individuals' utilization patterns of health care-only if they have used a health care provider in the last four weeks. Healthcare utilization could confound the results reported here. None-the-less, while we must acknowledge certain groups (eg, those with chronic conditions, older people or the disabled) are likely to use health care more, true financial protection should be equitable across groups. Further research into the exact costs and fees incurred by individuals and explanatory demographic variables is also needed.

Other data sources employed-including CNMS-are from administrative sources that may be prone to errors and issue of data quality. Additionally, as administrative data are only from public facilities, this study is not able to analyze private providers in the health system.

The analyses undertaken may also introduce potential errors. Logistic regression identifies associations through predictive probabilities between groups and outcomes, but cannot prove causality. Our results must be interpreted with this limitation in mind. Additionally, assumptions about grouping of outcomes-including OOP from informal and formal sources and between different services-may obscure finer trends and patterns, but due to small sample size it was not possible to analyze these subgroups separately. Even so, we use multiple covariates not to just examine potential inequities between demographic groups, but also to control for potential effects and elucidate clearer associations than descriptive trends. This allows us to identify whether it is age or employment status, for example, which is the stronger determinant of an outcome. Furthermore, we take into account the clustered nature of the survey design further strengthening the validity of our findings.

\section{CONCLUSIONS}

There is clear evidence that many elements of financial protection are not being met in Moldova. While in some areas-insurance coverage and OOP for services-there is slow improvement, but the increase in OOP for medicines counteracts the improvements observed. Healthcare is potentially being foregone due to limited protection from costs. Progress toward UHC is an integral to the SDGs [3], and removing financial barriers to access is key to attaining UHC. To reduce financial access barriers the Moldovan government should focus on three areas: further expansion of health insurance coverage, tackling costs of medicines and health care services, and improving the efficiency of health system financing. The first, further expansion of insurance coverage and access to services centers, can be achieved by further targeting of coverage to the uninsured, by utilizing incentives (both financial and using legal re- 
quirements), and by streamlining the enrolment process [27]. Our results indicate that these efforts in the past may have had only small gains, and marginal returns may be low. Alternatively, building upon the expansion and free entitlement to primary care services for all in 2009, insurance coverage could be extended free of charge maintaining inputs from taxation and insurance premiums. Moldova must weigh up the marginal costs of targeted insurance premiums vs expanding free entitlement on the pathway to UHC.

Second, costs for medicines and services could be reduced by: i) introducing regulations to prevent informal payments and to regularise formal cost-sharing [28]; ii) increasing, through allocated funding and legal powers, the powers of the Moldovan Medicines and Medical Devices Agency (MMDA) and CNAM, in procuring medicines, negotiating prices, and regulating quality, to reduce costs for those who purchase drugs and the cost burden of medicines in the benefit package $[23,29]$; iii) strengthening the provision of PHC, where the majority of health needs can be dealt with cost-effectively, in resource allocations for both services and medicines [28].

Third, health system financing trends indicate that although Moldova commits a proportion of public sources to health in line with EU averages, the actual amount is very low. The government fiscal space for increased funding of health system could be improved by: (i) increasing tobacco and alcohol taxes-which will not only reduce consumption and tackle the health burden of these substances, but generate revenues for the government, (ii) optimizing and consolidating the inefficient hospital sector (iii) investing in new infrastructure using EU development financing and private sector funding to improve health system efficiency.

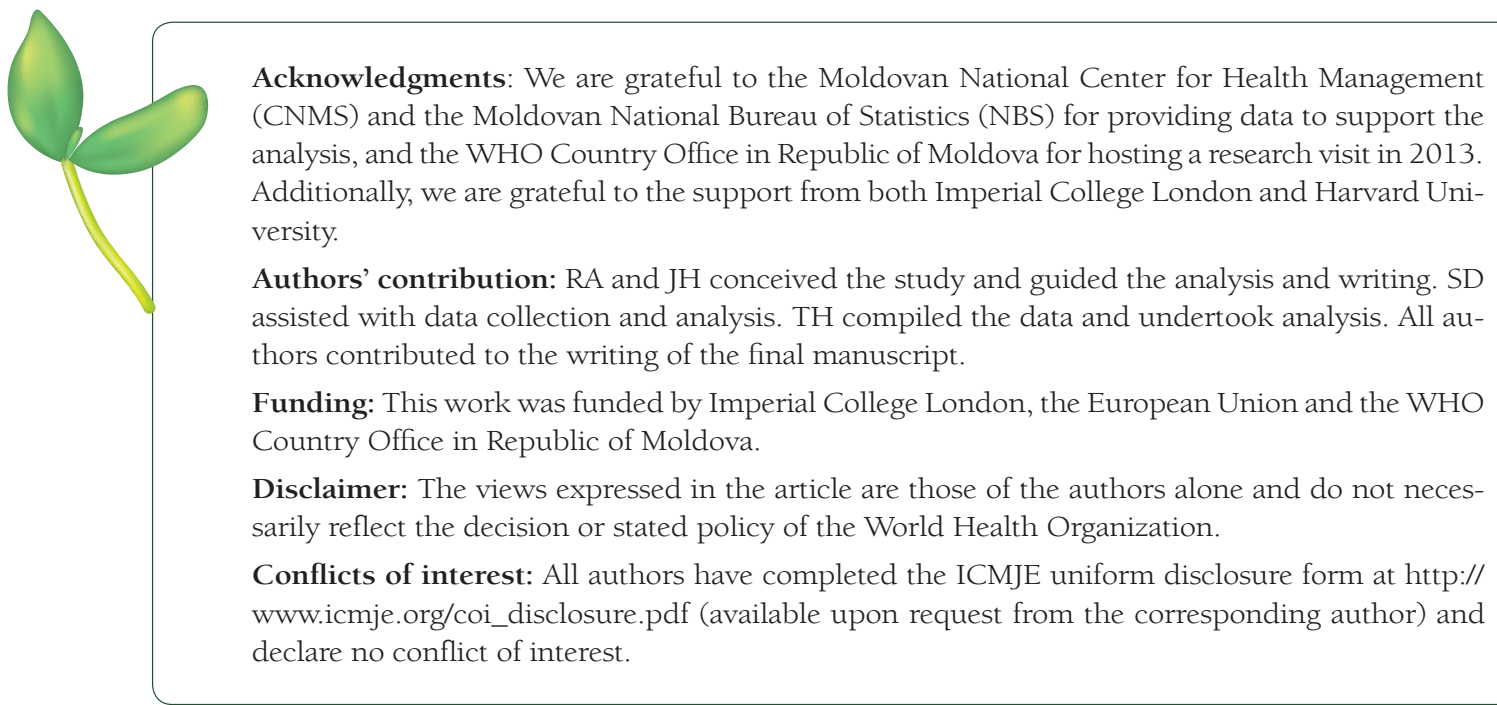

1 World Health Organization. The World Health Report 2013: Research for Universal Health Coverage. Geneva, Switzerland. World Health Organization, 2013.

2 World Health Organization. The World Health Report 2010: Health System Financing-The path to universal coverage. Geneva, Switzerland World Health Organization, 2010.

3 Tangcharoensathien V, Mills A, Palu T. Accelerating health equity: the key role of universal health coverage in the Sustainable Development Goals. BMC Med. 2015;13:101. Medline:25925656 doi:10.1186/s12916-0150342-3

4 Turcanu G, Domente S, Buga M, Richardson E. Republic of Moldova: health system review. Health Syst Transit. 2012;14:1-151. Medline:23211662

5 World Health Organization Regional Office for Europe. European Health for All database (HFA-DB). 2013. Available: http://data.euro.who.int/hfadb/. Accessed: August 2013.

6 Atun R, Richardson E, Shishkin S, Kacevicius G, Ciocanu M, Sava V. Republic of Moldova: health system review. Health Syst Transit. 2008;10:1-140. Medline:23211662

7 National Bureau of Statistics of the Republic of Moldova. StatBank. 2013. Available: http://www.statistica.md/. Accessed: 12 November 2013.

8 The World Bank. Migration \& Remittances Data. 2013. Available: http://go.worldbank.org/092X1CHHD0. Accessed: 11 August 2013.

9 The World Bank. DataBank: Country: Moldova. 2013. Available: http://data.worldbank.org/country/moldova. Accessed: 11 July 2013 
10 Atun R. What are the advantages and disadvantages of restructuring a health care system to be more focused on primary care services. Copenhagen, WHO Regional Office for Europe; 2004. Available: http://www.euro. who.int/_data/assets/pdf_file/0004/74704/E82997.pdf. Accessed: 11 August 2013.

11 Starfield B. Is primary care essential? Lancet. 1994;344:1129-33. Medline:7934497 doi:10.1016/S01406736(94)90634-3

12 Starfield B, Shi L, Macinko J. Contribution of primary care to health systems and health. Milbank Q. 2005;83:457-502. Medline:16202000 doi:10.1111/j.1468-0009.2005.00409.x

13 Vian T, Feeley FG, Domente S, Negruta A, Matei A, Habicht J. Barriers to universal health coverage in Republic of Moldova: a policy analysis of formal and informal out-of-pocket payments. BMC Health Serv Res. 2015;15:319. Medline:26260324 doi:10.1186/s12913-015-0984-z

14 Government of Republic of Moldova. National Health Policy 2007-2021. Chisinau, Republic of Moldova: Government of Republic of Moldova, 2007.

15 Government of Republic of Moldova. Healthcare System Development Strategy for the period 2008-2017. Chisinau, Republic of Moldova: Ministry of Health, 2007.

16 Atun R, de Andrade LO, Almeida G, Cotlear D, Dmytraczenko T, Frenz P, et al. Health-system reform and universal health coverage in Latin America. Lancet. 2015;385:1230-47. Medline:25458725 doi:10.1016/ S0140-6736(14)61646-9

17 Atun R, Aydın S, Chakraborty S, Sümer S, Aran M, Gürol I, et al. Universal health coverage in Turkey: enhancement of equity. Lancet. 2013;382:65-99. Medline:23810020 doi:10.1016/S0140-6736(13)61051-X

18 World Health Organization. Everybody's business—strengthening health systems to improve health outcomes: WHO's framework for action. Geneva: World Health Organization, 2007.

19 Roberts M, Hsiao W, Berman P, Reich M. Getting health reform right: a guide to improving performance and equity: Oxford University Press: Oxford; 2003.

20 The Moldovan National Center for Health Management (CNMS). Information systems. Chisinau, Moldova: Ministry of Health of the Republic of Moldova, 2013. Available: http://www.cnms.md/. Accessed: 11 August 2013.

21 Shishkin S, Jowett M. A review of health financing reforms in the Republic of Moldova. Copenhagen, Denmark: WHO Regional Office for Europe, 2012. Available: http://www.euro.who.int/_data/assets/pdf_ file/0009/166788/E96542.pdf. Accessed: 11 August 2013.

22 Richardson E, Roberts B, Sava V, Menon R, McKee M. Health insurance coverage and health care access in Moldova. Health Policy Plan. 2012;27:204-12. Medline:21441565 doi:10.1093/heapol/czr024

23 Sautenkova N, Ferrario A, Bolokhovets G, Kanavos P. Availability and affordability of medicines and assessment of quality systems for prescription of medicines in the Republic of Moldova. Republic of Moldova Health Policy Series 6. WHO Regional Office for Europe; 2012. Available: http://www.euro.who.int/en/health-topics/ Health-systems/medicines/publications2/2012/availability-and-affordability-of-medicines-and-assessment-ofquality-systems-for-prescription-of-medicines-in-the-republic-of-moldova-2012. Accessed: 11 August 2013.

24 Spaan E, Mathijssen J, Tromp N, McBain F. Have At, Baltussen R. The impact of health insurance in Africa and Asia: a systematic review. Bull World Health Organ. 2012;90:685-92. Medline:22984313 doi:10.2471/ BLT.12.102301

25 Ekman B. Community-based health insurance in low-income countries: a systematic review of the evidence. Health Policy Plan. 2004;19:249-70. Medline:15310661 doi:10.1093/heapol/czh031

26 Acharya A, Vellakkal S, Taylor F, Masset E, Satija A, Burke M, et al. The impact of health insurance schemes for the informal sector in low- and middle-income countries: a systematic review. London: University of London, Institute of Education, Social Science Research Unit. EPPI-Centre Report; 2006. 2012.

27 Vilcu I, Mathauer I. State budget transfers to Health Insurance Funds for universal health coverage: institutional design patterns and challenges of covering those outside the formal sector in Eastern European highincome countries. Int J Equity Health. 2016;15:7. Medline:26767970 doi:10.1186/s12939-016-0295-y. Erratum in: Int J Equity Health. 2016;15:43.

28 Ferrario A, Chitan E, Seicas R, Sautenkova N, Bezverhni Z, Kluge H, et al. Progress in increasing affordability of medicines for non-communicable diseases since the introduction of mandatory health insurance in the Republic of Moldova. Health Policy Plan. 2016;2016:czv136. epub. Medline:26830363 doi:10.1093/heapol/ czv136

29 Ferrario A, Sautenkova N, Bezverhni Z, Seicas R, Habicht J, Kanavos P, et al. An in-depth analysis of pharmaceutical regulation in the Republic of Moldova. J Pharm Policy Pract. 2014;7:4. Medline:25848544 doi:10.1186/2052-3211-7-4 